NBER WORKING PAPER SERIES

\title{
THE IMPACT OF NEW LABORATORY PROCEDURES AND OTHER MEDICAL INNOVATIONS ON THE HEALTH OF AMERICANS, 1990-2003: EVIDENCE FROM LONGITUDINAL, DISEASE-LEVEL DATA
}

Frank R. Lichtenberg

Working Paper 12120

http://www.nber.org/papers/w12120

\author{
NATIONAL BUREAU OF ECONOMIC RESEARCH \\ 1050 Massachusetts Avenue \\ Cambridge, MA 02138 \\ March 2006
}

The author gratefully acknowledges research support for this project received from the Laboratory Health Care Coalition, which had no role in the design of the study, the collection, analysis, and interpretation of the data, or the preparation or approval of the manuscript for publication. The views expressed herein are those of the author(s) and do not necessarily reflect the views of the National Bureau of Economic Research.

(C2006 by Frank R. Lichtenberg. All rights reserved. Short sections of text, not to exceed two paragraphs, may be quoted without explicit permission provided that full credit, including (C) notice, is given to the source. 
The Impact of New Laboratory Procedures and Other Medical Innovations on the Health of Americans, 1990-2003: Evidence from Longitudinal, Disease-Level Data

Frank R. Lichtenberg

NBER Working Paper No. 12120

March 2006

JEL No. I12, J1, O33

\begin{abstract}
$\underline{\text { ABSTRACT }}$
This study examines the effect of the introduction of new laboratory procedures and other medical goods and services on the health of Americans during the period 1990-2003. We hypothesize that, the more medical innovation there is related to a medical condition, the greater the improvement in the average health of people with that condition. To test this hypothesis, we estimate models of health outcomes using longitudinal disease-level data. We measure innovation in five types of medical procedures or products: pathology \& laboratory procedures, outpatient prescription drugs, inpatient prescription drugs, surgical procedures, and diagnostic radiology procedures.

We examine two kinds of (inverse) indicators of health: mortality and disability. The mortality indicator we analyze is the mean age at death of people whose underlying cause of death is medical condition i. The disability measures we analyze are the fraction of people with medical condition i who (1) missed work, or (2) spent one or more days in bed, due to that condition.

Our estimates indicate that conditions with higher rates of lab and outpatient drug innovation had larger increases in mean age at death, controlling for other medical innovation rates and initial mean age at death. The 1990-1998 increase in mean age at death attributable to use of new lab procedures is estimated to be about 6 months. This is $42 \%$ of the total increase in mean age at death (1.18 years) in our sample of diseases. New laboratory procedures introduced during 1990-1998 are estimated to have saved 1.13 million life-years in 1998. Expenditure per life-year gained from new lab procedures is estimated to be $\$ 6093$. Treatments that cost this amount are generally considered to be quite cost-effective.

In the analysis of disability, when we don't control for the initial level of disability, we find that conditions with higher rates of lab and outpatient innovation had greater declines in the probability of missing work during 1996-2003. This suggests that the use of new laboratory procedures reduced the number of work-loss days in 2003 by 42 million. When we control for initial disability, the inverse relationship between lab innovation and disability changes disappears. This is because there is a significant inverse relationship between initial health and the extent of laboratory innovation. But due to errors in measuring initial health, controlling for this variable may cause the impact of innovation on health to be underestimated.
\end{abstract}

Frank R. Lichtenberg

Graduate School of Business

Columbia University

614 Uris Hall

3022 Broadway

New York, NY 10027

and NBER

fr11@ columbia.edu 
Economists believe that the development of new products is the main reason why people are better off today than they were several generations ago. In their 1993 book, Innovation and Growth in the Global Economy, Grossman and Helpman argued that “innovative goods are better than older products simply because they provide more 'product services' in relation to their cost of production.” In their 1996 book, The Economics of New Goods, Bresnahan and Gordon stated simply that "new goods are at the heart of economic progress.” And in a recent paper, Measuring the Growth from Better and Better Goods, Bils (2004) makes the case that "much of economic growth occurs through growth in quality as new models of consumer goods replace older, sometimes inferior, models.”

New goods do not emerge ex nihilo. They are usually the result of investment in research and development $(\mathrm{R} \& D)$. National Science Foundation data reveal that the medical equipment and supplies industry is one of the most research-intensive industries in the economy. As Figure 1 indicates, the ratio of $R \& D$ expenditure to sales is two and a half times as high in this industry as it is in the average American industry.

In this paper I will examine the impact of a subset of the new products generated by this industry — clinical laboratory products — on the longevity and quality of life of Americans. FDA data indicate that, in the last decade, about 100 of these new products have been introduced. I hypothesize that these new products have improved the quality of information physicians and patients have about patients' medical conditions, and have therefore enabled more appropriate and effective treatment of those conditions. This may be illustrated by two new kinds of tests: HIV tests, and genetic tests related to dosing of a widely prescribed anti-blood clotting drug.

For almost two decades, HIV tests had two glaring flaws. They did not detect the earliest stage of infection, when people are more likely to spread the virus. They also took days to produce results, and many people never returned to learn whether they were infected. New generations of tests can largely eliminate either the long waiting time for results, or the failure to find early infections (but not both) (New York Times (2005a)).

About two million Americans take warfarin (Coumadin) each day to help prevent blood clots because of problems like a heart attack, an abnormal heart rhythm, a stroke or major surgery. Establishing a proper dose of warfarin as patients start taking the drug is 
one of the peskiest problems in medical practice. Misjudgments in doses can critically affect the clotting mechanism, leading to potentially fatal bleeding. At present, doctors rely on costly blood tests that must be repeated frequently over a period of months to adjust the dose to ensure that the drug will work safely. But a recent study suggests that it may be possible to develop a standard genetic test that would allow doctors to quickly and precisely choose a safe starting dose of warfarin (New York Times (2005b)).

This study will examine the effect of the introduction of new laboratory procedures and other medical goods and services on the health of Americans during the period 1990-2003.

\section{Econometric specification}

We hypothesize that, the more medical innovation there is related to a medical condition, the greater the improvement in the average health of people with that condition. To test this hypothesis, we will estimate the following model, using longitudinal disease-level data:

$$
\mathrm{H}_{-} \mathrm{END}_{\mathrm{i}}-\mathrm{H} \_\mathrm{BEGIN} \mathrm{i}=\alpha+\sum_{\mathrm{j}} \beta_{\mathrm{j}} \mathrm{INNOV}_{\mathrm{ji}}+\gamma \mathrm{Z}_{\mathrm{i}}+\varepsilon_{\mathrm{i}}
$$

where

$\mathrm{H}_{\text {ENND }} \mathrm{E}=\mathrm{a}$ measure of the average health of people with medical condition $\mathrm{i}$ at the end of a period

H_BEGIN ${ }_{\mathrm{i}}=$ a measure of the average health of people with medical condition $\mathrm{i}$ at the beginning of the period

INNOV $_{\mathrm{ji}}=\mathrm{a}$ measure of innovation of type $\mathrm{j}$ in the treatment of condition i during the period

$\mathrm{Z}_{\mathrm{i}} \quad=$ other attributes of medical condition $\mathrm{i}$

We will measure innovation in five types of medical procedures or products $(j=1, \ldots, 5)$ : pathology \& laboratory procedures (henceforth referred to as lab procedures), outpatient prescription drugs, drugs administered by providers (e.g. chemotherapy; henceforth referred to as inpatient prescription drugs), surgical procedures, and diagnostic radiology procedures. 
We will examine two kinds of (inverse) indicators of health: mortality and disability. The mortality indicator we will analyze is the mean age at death of people whose underlying cause of death is medical condition i. Data on mean age at death (and the number of deaths), by cause, were obtained from the Multiple Cause-of-Death Mortality Data from the National Vital Statistics System of the National Center for Health Statistics. Each record in the micro data is based on information abstracted from death certificates filed in vital statistics offices of each State and District of Columbia. Causes of death were coded according to the International Classification of Diseases, Ninth Revision 1979-1998. The average number of records (deaths) per year is about 2.3 million.

The disability measures we will analyze are the fraction of people with medical condition i who (1) missed work, or (2) spent one or more days in bed, due to that condition. These data were constructed from the Medical Conditions files of the 1996 and 2003 waves of the Medical Expenditure Panel Survey (MEPS).

Eq. (1) will be estimated via weighted least-squares, where the weight is equal to the mean number of observations from which the dependent variable was computed $\left(\left(\mathrm{N}_{\text {B BEGIN }}+\mathrm{N} \_\mathrm{END}_{\mathrm{i}}\right) / 2\right)$. In the mortality analysis, the weight is the mean of the number of 1990 and 1998 deaths due to underlying cause i. In the disability analysis, the weight is the mean of the number of records in the 1996 and 2003 Medical Conditions files associated with condition i. The data are consistent with the hypothesis that the variance of $\left(\mathrm{H} \_E N D_{\mathrm{i}}-\mathrm{H} \_B E G I N_{\mathrm{i}}\right)$ is inversely proportional to $\left(\left(\mathrm{N} \_B E G I N_{\mathrm{i}}+\right.\right.$ N_END $\left.D_{i}\right) / 2$ ). Figure 1 depicts the relationship across conditions between the 1990-1998 change in the mean age at death and the mean number of deaths. The variance of the change in the mean age at death is much lower for conditions causing a larger number of deaths.

Measures of innovation in the treatment of a condition during a period were constructed as follows:

$$
\mathrm{INNOV}_{\mathrm{ji}}=\sum_{\mathrm{p}} \mathrm{FREQ}_{\mathrm{pji}} \mathrm{NEW}_{\mathrm{p}} / \sum_{\mathrm{p}} \mathrm{FREQ}_{\mathrm{pji}}
$$

where

$\mathrm{FREQ}_{\mathrm{pji}}=$ the number of times procedure $\mathrm{p}$ of type $\mathrm{j}$ was performed on patients with diagnosis $i$ in the last year of a period 
$\mathrm{NEW}_{\mathrm{p}}=1$ if the CPT code for procedure $\mathrm{p}$ was established by the AMA after the beginning of the period

$=0$ otherwise

Data on utilization of medical procedures and products, by diagnosis (FREQ $\mathrm{pji}_{\mathrm{p}}$ ), were obtained from the MEDSTAT Marketscan database. MEDSTAT contains data on outpatient and inpatient services (procedures) and outpatient prescriptions of hundreds of thousands, or even millions, of individuals. Each outpatient and inpatient service record contains one procedure code (usually a CPT code), one or more ICD-9 diagnosis codes, and the amount paid for the procedure. Hence, we can compute the frequency of procedures performed (and expenditure), by CPT code and ICD-9 code, in each year (1990-2003).

The year in which CPT codes for laboratory, surgery, and radiology procedures were first established by the American Medical Association was determined from the AMA's publication CPT Assistant Archives 1990-2003. To illustrate the data contained therein, here is information about the first seven hematology and coagulation procedures (a subset of lab procedures) listed:

\begin{tabular}{|l|r|}
\hline CPT code and description & $\begin{array}{r}\text { Year CPT code } \\
\text { was established }\end{array}$ \\
\hline 85002 Bleeding time & Pre-1990 \\
\hline 85004 Blood count; automated differential WBC count & Pre-1990 \\
\hline 85005 Blood count; basophil count, direct & Pre-1990 \\
\hline $\begin{array}{l}\text { 85007 Blood count; blood smear, microscopic examination with } \\
\text { manual differential WBC count }\end{array}$ & 1993 \\
\hline $\begin{array}{l}\text { 85008 Blood count; blood smear, microscopic examination } \\
\text { without manual differential WBC count }\end{array}$ & Pre-1990 \\
\hline 85009 Blood count; manual differential WBC count, buffy coat & Pre-1990 \\
\hline 85012 Blood count; eosinophil count, direct & \\
\hline
\end{tabular}

A similar method was used to determine the vintage of drugs administered by providers (e.g. chemotherapy), which are also reported in outpatient and inpatient services files. However the codes for these procedures are not CPT codes established by the AMA, and the dates the codes were established are not reported in CPT Assistant Archives 1990-2003. These codes are Healthcare Common Procedure Coding System 
(HCPCS) Level II Codes. ${ }^{1}$ We used Multum’s Lexicon database

(http://www.multum.com/Lexicon.htm) to determine the active ingredients of the drugs corresponding to each of these HCPCS Level II Codes. We used data from the Drugs@FDA database (http://www.fda.gov/cder/drugsatfda/datafiles/default.htm) to determine the year in which each active ingredient was first approved by the FDA.

MEDSTAT outpatient prescription drug claims do not include diagnosis codes, so we used a different source of data on outpatient prescription drugs that links prescriptions written with diagnoses: the National Ambulatory Medical Care Survey (NAMCS).

\section{Sample characteristics}

We have data on utilization of medical procedures and products during the period 1990-2003. However, the sample period for the mortality analysis is restricted to 19901998, and the sample period for the disability analysis is restricted to 1996-2003.

The initial year for the mortality analysis is 1990 because the data on the dates at which CPT codes were established are left-censored: if a CPT code was established before 1990, we can't determine the year in which it was established. The final year is 1998 because the disease classification system used to code underlying cause-of-death for deaths that occurred after 1998 is different from that used to code underlying cause-ofdeath for deaths that occurred earlier and from that used to code patient diagnoses in MEDSTAT, NAMCS, and MEPS.

The disease classification system used to code underlying cause-of-death for deaths that occurred in the United States during 1979-98, and to code patient diagnoses in MEDSTAT, NAMCS, and MEPS data, is the Ninth Revision of the International Classification of Diseases (ICD-9). The Tenth Revision of the ICD (ICD-10) was used to

\footnotetext{
${ }^{1}$ Level II of the HCPCS is a standardized coding system that is used primarily to identify products, supplies, and services not included in the CPT codes, such as ambulance services and durable medical equipment, prosthetics, orthotics, and supplies (DMEPOS) when used outside a physician's office. Because Medicare and other insurers cover a variety of services, supplies, and equipment that are not identified by CPT codes, the level II HCPCS codes were established for submitting claims for these items. The development and use of level II of the HCPCS began in the 1980's. Level II codes are also referred to as alpha-numeric codes because they consist of a single alphabetical letter followed by 4 numeric digits, while CPT codes are identified using 5 numeric digits. See http://www.cms.hhs.gov/medicare/hcpcs/codpayproc.asp
} 
code underlying cause-of-death for deaths that occurred in 1999 and later years. The ICD-9 and ICD-10 classification systems are quite different. The ICD-9 system has a 4digit numeric structure and about 5,000 categories for classifying cause-of-death. The ICD-10 system has a 4-digit alphanumeric coding structure and about 8,000 categories for classifying cause-of-death. Comparison of ICD-9 and ICD-10 shows that new chapters have been added to the ICD, old chapters have been rearranged, causes of death have been regrouped, and titles have changed. As a result of these changes, the two classification schemes are different enough to make direct comparisons of cause-of-death difficult. $^{2}$

The sample period for the disability analysis is restricted to 1996-2003, because 1996 was the first year in which the MEPS was conducted.

We will analyze data at the 3-digit ICD-9 level. ${ }^{3}$ We exclude medical conditions due to injury and poisoning (ICD-9 codes 800-999). The models we estimate will be based on data on about 400 diseases.

\section{Descriptive statistics}

Table 1 shows data on procedures performed in 1998, by type and vintage. In 1998, the MEDSTAT data covered 92 firms. About 22 million outpatient and inpatient lab, surgical, drug, and diagnostic radiology procedures were performed on the people covered by these firms' health plans. The total cost of these procedures was $\$ 1.94$ billion. About 22\% of the laboratory procedures performed had CPT codes that were established by the AMA after 1990. The average cost of new lab procedures was only $\$ 1$ higher than the average cost of old lab procedures (\$24). For other types of procedures, the average cost of new procedures was 1.8 to 11.0 times as high as the average cost of old procedures. Lab procedures account for $60 \%$ of the total number of procedures performed, but only $17 \%$ of total expenditure on these procedures.

\footnotetext{
${ }^{2}$ See http://wonder.cdc.gov/wonder/help/mort.html\#Compressed\%20Mortality\%20File:\%20ICD\%20Revision ${ }^{3}$ For a list of 3-digit ICD-9 disease codes and names, see http://www.disabilitydurations.com/icd9top.htm.
} 
About 1100 distinct lab tests (CPT codes) appear in the 1998 MEDSTAT data. Table 2 lists the 20 lab procedures performed in 1998 with the highest total cost. Table 3 lists the 20 post-1990 lab procedures performed in 1998 with the highest total cost.

Table 4 shows summary mortality and innovation statistics for the sample of 3digit ICD-9 diseases during the period 1990-1998. Table 5 shows mortality and laboratory innovation data for the 30 largest causes of death. Note that the extent of laboratory innovation varied considerably across diseases. For some diseases, less than $16 \%$ of lab procedures were post-1990 procedures. In contrast, $33 \%$ of the lab procedures for prostate cancer, and $41 \%$ of the lab procedures for HIV, were post-1990 procedures.

\section{Mortality results}

Estimates of models of the 1990-1998 change in mean age at death are presented in Table 6. We estimated four different models. All models include five innovation measures (lab procedures, outpatient rx, inpatient rx, surgical procedures, and diagnostic radiology procedures), and the 1990-1998 change in the log of the number of deaths.

HIV is included in models 1 and 2, but excluded from models 3 and 4. As shown in Table 5, among high-mortality diseases HIV is an outlier in terms of both laboratory innovation and increase in mean age at death. It is therefore of interest to assess the sensitivity of the estimates to the inclusion of this observation.

Eq. (1) may be viewed as a special case of the following equation, in which the restriction $\pi=1$ is imposed:

$$
\mathrm{H} \_E N D_{\mathrm{i}}=\alpha+\sum_{\mathrm{j}} \beta_{\mathrm{j}} \mathrm{INNOV}_{\mathrm{ji}}+\gamma \mathrm{Z}_{\mathrm{i}}+\pi \mathrm{H} \_\mathrm{BEGIN} \mathrm{i}_{\mathrm{i}}+\varepsilon_{\mathrm{i}}
$$

or

$$
\mathrm{H}_{-} \mathrm{END}_{\mathrm{i}}-\mathrm{H} \_\mathrm{BEGIN} \mathrm{i}=\alpha+\sum_{\mathrm{j}} \beta_{\mathrm{j}} \mathrm{INNOV}_{\mathrm{ji}}+\gamma \mathrm{Z}_{\mathrm{i}}+(\pi-1) \mathrm{H} \_\mathrm{BEGIN} \mathrm{i}_{\mathrm{i}}+\varepsilon_{\mathrm{i}}
$$

Inclusion of H_BEGIN in eq. (4) is referred to as "baseline adjustment”. Arguments can be made both for and against baseline adjustment. The argument for is that mean age at death may be subject to regression to the mean: diseases with high initial mean ages at death are likely to experience smaller increases in mean age at death $(\pi<1)$. If this is 
true, and innovation is correlated with initial mean age at death, imposing the restriction $\pi=1$ may result in biased estimates of the $\beta$ 's. In particular, if innovation is inversely related to initial mean age at death-there is more innovation for diseases with the worst initial health — then the $\beta$ 's may be overestimated.

In our sample, there is a significant inverse relationship between initial health (e.g. mean age at death) and the extent of laboratory and inpatient rx innovation: the rates of innovation (\% of new procedures) are highest for diseases with the worst initial health. Initial health is uncorrelated with the rates of outpatient rx and diagnostic radiology innovation, and positively correlated with surgical innovation: there was more surgical innovation for diseases with high initial mean ages at death.

If H_BEGIN were measured without error, estimates of $\beta_{\mathrm{j}}$ 's from the unrestricted model (4) would be more reliable than estimates from the restricted model (1). In practice, however, H_BEGIN is measured with error. In the presence of measurement error, the estimate of $\pi$ is biased towards zero: the estimate of $\pi$ will be significantly less than 1 even when true $\pi=1$. Moreover, the bias will be transmitted to estimates of coefficients on other regressors that are correlated with H_BEGIN. In particular, coefficients on other regressors that are negatively correlated with H_BEGIN will also be biased towards zero.

Previous investigators have recognized the potential pitfalls of baseline adjustment. Campbell and Kenny (2002) argued there "are instances when problems are actually created, instead of solved, by 'correction' for regression toward the mean.” And Glymour et al (2005) concluded that

In many plausible situations, baseline adjustment induces a spurious statistical association between [the treatment measure] and change in [outcome]. More generally, when exposures are associated with baseline health status, this bias can arise if change in health status preceded baseline assessment or if the dependent variable measurement is unreliable or unstable. In some cases, change-score analyses without baseline adjustment provide unbiased causal effect estimates when baseline-adjusted estimates are biased.

Models 1 and 3 do not control for initial health (mean age at death in 1990); models 2 and 4 do. The true effect of innovation on health may be bounded between estimates from models that don't and do control for initial health. 
Consider the estimates of Model 1 in Table 6. The coefficients on laboratory, outpatient rx, and inpatient rx innovation are positive and highly significant: diseases with above-average rates of these types of innovation had above-average increases in mean age at death. The coefficient on diagnostic radiology innovation is only marginally significant (p-value $=.16$ ), and the coefficient on surgical innovation is not significant. ${ }^{4}$ The positive coefficient on the 1990-1998 change in the log of the number of deaths indicates that diseases with larger percentage increases in the number of deaths tended to have larger increases in mean age at death.

Model 2 controls for initial mean age at death, and (like Model 1) is based on a sample including HIV. Not surprisingly, the coefficient on initial health is negative and highly significant: mean age at death increased more for diseases with low initial ages. Controlling for initial health has little effect on the outpatient rx coefficient. However, it reduces the magnitude of the lab innovation coefficient by about 50\%, and the coefficient on inpatient rx innovation is no longer significant. The lab innovation coefficient is now significant at the $6 \%$ level.

Model 3 excludes HIV and does not control for initial health. The estimates are similar to the estimates of Model 1, but the coefficients on lab and outpatient rx innovation are about 20\% smaller when HIV is excluded. Model 4 excludes HIV and controls for initial health. The estimates are similar to the estimates of Model 2.

To summarize the estimates, in all four models, the coefficients on lab innovation and outpatient rx innovation are positive and significant at at least the 6\% level; in some models these coefficients are much more significant. Controlling for initial health reduces the magnitude and significance of the lab and (especially) the inpatient rx

\footnotetext{
${ }^{4}$ Measuring surgical innovation using CPT code changes may be problematic. Closer inspection of the data on surgical procedures reveals that some "new" procedures are probably just relabeled or reclassified old procedures, rather than true innovations. For example, the three procedures whose codes were added in 1997 which were most frequently performed in 1997 were 98940, 98941, and 98942, which correspond to different types of chiropractic manipulative treatment of the spine. Undoubtedly, this type of treatment was performed well before 1997. A new CPT code should therefore be considered a necessary condition for a medical innovation, but not a sufficient condition: all innovations have new CPT codes, but some new CPT codes are not innovations. The fraction of procedures with new CPT codes exceeds the fraction of truly innovative procedures, perhaps by a significant amount, and the degree of overstatement varies across diseases. In the future, I hope to develop a reliable method of distinguishing between truly innovative procedures and old procedures with new CPT codes.
} 
innovation coefficients, but if poor initial health stimulates innovation, controlling for initial health may bias these coefficients downward.

Now we will assess the implications of the estimates of Model 2, which has the lowest lab innovation coefficient and the second lowest outpatient rx coefficient. As shown in Table 4, 20\% of the lab procedures performed in 1998 were post-1990 procedures. The 1990-1998 increase in mean age at death attributable to use of new lab procedures is estimated to be 0.49 years $(=2.44 * 0.20)$. This is $42 \%$ of the total increase in mean age at death (1.18 years) in our sample of diseases. There were 2.31 million deaths in the U.S. in 1998. If each of the 2.31 million people who died in 1998 lived 0.49 years longer due to 1990-1998 laboratory innovations, then these innovations saved 1.13 million (= $0.49 * 2.31$ million) life-years in 1998 .

The following table shows U.S. laboratory revenues during the period 1997$2003^{5}:$

\begin{tabular}{|l|r|}
\hline Year & U.S. Laboratory Revenues (\$ Billions) \\
\hline 1997 & $\$ 30.6$ \\
\hline 1998 & $\$ 30.6$ \\
\hline 1999 & $\$ 30.7$ \\
\hline 2000 & $\$ 32.9$ \\
\hline 2001 & $\$ 35.4$ \\
\hline 2002 & $\$ 38.1$ \\
\hline 2003 & $\$ 40.1$ \\
\hline
\end{tabular}

Total laboratory revenue was $\$ 30.6$ billion in 1998. The data shown in Table 1 imply that 22.5\% of 1998 expenditure on laboratory procedures was spent on post-1990 procedures. Hence, about $\$ 6.9$ billion (= 22.5\% * \$30.6 billion) was spent on post-1990 lab procedures in 1998. Expenditure per life-year gained from new lab procedures is therefore $\$ 6093$ (= $\$ 6.9$ billion / 1.13 million life-years). Treatments that cost this amount are generally considered to be quite cost-effective.

\footnotetext{
${ }^{5}$ Source: "Lab Industry Strategic Outlook 2005: Market Trends \& Analysis" Author: Jondavid Klipp. Published in 2004 by "Washington G-2 Reports", New York, NY. In 2003, the distribution of revenue by type of lab was:

Hospital Labs $\quad 54 \%$

Independent Labs $\quad 32 \%$

Physician Office Labs $\quad 7 \%$

Other (e.g. Nursing Home, Public Health) 7\%

Due to the DRG reimbursement structure, estimation of revenues for hospital labs is difficult.
} 


\section{Disability results}

Table 7 shows summary disability and innovation statistics for the sample of 335 3-digit ICD-9 diseases during the period 1996-2003. The disability statistics are based on a much smaller number of individual-level observations than the mortality statistics: the combined number of condition records in the 1996 and 2003 MEPS Medical Conditions Files with non-missing disability data is 182,689 . The rate of lab innovation during 1996-2003 was similar to the rate of lab innovation during 1990-1998. Nineteen percent of the lab procedures performed in 2003 had CPT codes that were added after 1996. But the other rates of innovation were lower: 19\% of outpatient rx's consumed in 1998 were for drugs introduced after 1990, but only 12\% of outpatient rx’s consumed in 2003 were for drugs introduced after 1996.

Estimates of models of the 1996-2003 change in the fraction of people who missed work or had bed days due to a condition are presented in Table 8. We estimated models both excluding and including the level of disability in 1996. All models include five 1996-2003 innovation measures (lab procedures, outpatient rx, inpatient rx, surgical procedures, and diagnostic radiology procedures), and the 1996-2003 change in the log of the number of people with the condition.

In Model 1, the dependent variable is the 1996-2003 change in the fraction of people who missed work, and we don't control for the level of disability in 1996. The coefficient on lab innovation is negative and significant at the $2 \%$ level, and the coefficient on outpatient rx innovation is negative and significant at the $6 \%$ level. This implies that conditions with higher rates of lab and outpatient innovation had greater declines in the probability of missing work during 1996-2003. Lab innovation during 1996-2003 is estimated to have reduced the probability of missing work in 2003 by .0092 $(=0.048 * 0.19)$. The average probability of missing work during this period was about $13 \%$, so this represents about a $7 \%(=.0092 / .13)$ reduction in the probability of missing work. The CDC estimates that there were about 598 million work-loss days in 2003 (Lethbridge-Çejku and Vickerie (2005, Table 17)). This suggests that the use of new laboratory procedures reduced the number of work-loss days in 2003 by 42 million (= $7 \%$ * 598 million). 
In Model 2, the dependent variable is the 1996-2003 change in the fraction of people who had any bed days, and we again don't control for the level of disability in 1996. The lab innovation coefficient is somewhat smaller, and is significant at the $7 \%$

level. This suggests that conditions with higher rates of lab innovation during 1996-2003 had greater declines in the probability of having bed days.

Models 3 and 4 control for the level of disability in 1996. When we control for initial disability, the lab and drug innovation coefficients are all statistically insignificant. In this sample, as in the mortality sample, there is a significant inverse relationship between initial health and the extent of laboratory innovation: the \% of new lab procedures is higher for diseases with the highest initial rates of missed work and bed days. Due to errors in measuring initial health, controlling for this variable may cause the impact of innovation on health to be underestimated.

\section{Summary}

This study has examined the effect of the introduction of new laboratory procedures and other medical goods and services on the health of Americans during the period 1990-2003. We hypothesized that, the more medical innovation there is related to a medical condition, the greater the improvement in the average health of people with that condition. To test this hypothesis, we estimated models of health outcomes using longitudinal disease-level data. We measured innovation in five types of medical procedures or products: pathology \& laboratory procedures, outpatient prescription drugs, inpatient prescription drugs, surgical procedures, and diagnostic radiology procedures.

We examined two kinds of (inverse) indicators of health: mortality and disability. The mortality indicator we analyzed is the mean age at death of people whose underlying cause of death is medical condition i. The disability measures we analyzed are the fraction of people with medical condition i who (1) missed work, or (2) spent one or more days in bed, due to that condition.

Our estimates indicated that conditions with higher rates of lab and outpatient drug innovation had larger increases in mean age at death, controlling for other medical innovation rates and initial mean age at death. The 1990-1998 increase in mean age at 
death attributable to use of new lab procedures is estimated to be about 6 months. This is $42 \%$ of the total increase in mean age at death (1.18 years) in our sample of diseases. New laboratory procedures introduced during 1990-1998 are estimated to have saved 1.13 million life-years in 1998. Expenditure per life-year gained from new lab procedures is estimated to be $\$ 6093$. Treatments that cost this amount are generally considered to be quite cost-effective.

In the analysis of disability, when we didn't control for the initial level of disability, we found that conditions with higher rates of lab and outpatient innovation had greater declines in the probability of missing work during 1996-2003. This suggested that the use of new laboratory procedures reduced the number of work-loss days in 2003 by 42 million. When we controlled for initial disability, the inverse relationship between lab innovation and disability changes disappeared. This is because there is a significant inverse relationship between initial health and the extent of laboratory innovation. Due to errors in measuring initial health, controlling for this variable may cause the impact of innovation on health to be underestimated. 


\section{References}

American Medical Association, CPT Assistant Archives 1990-2003 Software.

Bils, Mark (2004), “Measuring the Growth from Better and Better Goods,” NBER working paper no.10606, July, http://www.nber.org/papers/w10606.

Bresnahan, Timothy F., and Robert J. Gordon (1996), The Economics of New Goods (Chicago: University of Chicago Press).

Campbell, Donald T., and David A. Kenny (2002), A Primer on Regression Artifacts (Guilford Press).

Centers for Disease Control, Compressed Mortality File 1979-1998, http://wonder.cdc.gov/wonder/help/mort.html\#Compressed\%20Mortality\%20File:\%20IC D\%20Revision

Glymour, M. Maria, et al (2005), "When Is Baseline Adjustment Useful in Analyses of Change? An Example with Education and Cognitive Change,” American Journal of Epidemiology Vol. 162, No. 3.

Grossman, Gene M., and Elhanan Helpman (1993), Innovation and Growth in the Global Economy (Cambridge: MIT Press).

Klipp, Jondavid (2004), Lab Industry Strategic Outlook 2005: Market Trends \& Analysis, (Washington G-2 Reports", New York, NY).

Lethbridge-Çejku M, Vickerie J (2005). Summary health statistics for U.S. adults: National Health Interview Survey, 2003. National Center for Health Statistics. Vital Health Stat 10 (225).

New York Times (2005a), “H.I.V. Tests Pose Choice of Breakthroughs,” June 6.

New York Times (2005b), "Study Suggests Gene Tests Could Ease Use of Anti-Clotting Drug,” June 2. 
Figure 1

The relationship across conditions between the

1990-1998 change in the mean age at death and the mean number of deaths




Table 1

Procedures performed in 1998, by type and vintage

\begin{tabular}{|c|c|c|c|}
\hline type & post1990 $=0$ & post1990=1 & all \\
\hline & \multicolumn{3}{|c|}{ Number of procedures } \\
\hline Pathology \& laboratory & $10,352,876$ & $2,898,617$ & $13,251,493$ \\
\hline Drugs administered by providers & 355,259 & 33,457 & 388,716 \\
\hline Surgery & $4,206,445$ & 539,415 & $4,745,860$ \\
\hline \multirow[t]{2}{*}{ Radiology--Diagnostic } & $3,689,574$ & 120,960 & $3,810,534$ \\
\hline & \multicolumn{3}{|c|}{ Total expenditure } \\
\hline Pathology \& laboratory & $\$ 249,408,303$ & $\$ 72,482,882$ & $321,891,185$ \\
\hline Drugs administered by providers & $\$ 19,097,036$ & $\$ 19,724,219$ & $38,821,255$ \\
\hline Surgery & $\$ 988,987,966$ & $\$ 232,978,135$ & $1,221,966,101$ \\
\hline \multirow[t]{2}{*}{ Radiology--Diagnostic } & $\$ 322,288,564$ & $\$ 39,734,802$ & $362,023,366$ \\
\hline & \multicolumn{3}{|c|}{ Average price } \\
\hline Pathology \& laboratory & $\$ 24$ & $\$ 25$ & $\$ 24$ \\
\hline Drugs administered by providers & $\$ 54$ & $\$ 590$ & $\$ 100$ \\
\hline Surgery & $\$ 235$ & $\$ 432$ & $\$ 257$ \\
\hline Radiology--Diagnostic & $\$ 87$ & $\$ 328$ & $\$ 95$ \\
\hline
\end{tabular}


Table 2

20 lab procedures performed in 1998 with highest total cost

\begin{tabular}{|c|c|c|c|c|c|}
\hline cpt & description & Number of procs. & Total cost & Avge. cost & year_added \\
\hline 88305 & $\begin{array}{l}\text { Level IV - Surgical pathology, gross and microscopic } \\
\text { examinationAbortion - Spontaneous/MissedArtery, }\end{array}$ & 421,385 & $\$ 47,280,735$ & $\$ 112$ & pre-1990 \\
\hline 80061 & $\begin{array}{l}\text { Lipid panelThis panel must include the } \\
\text { following:Cholesterol, serum, total } \\
\text { (82465)Lipoprotein, dire }\end{array}$ & 558,944 & $\$ 15,107,078$ & $\$ 27$ & pre-1990 \\
\hline 85025 & $\begin{array}{l}\text { Blood count; complete (CBC), automated (Hgb, Hct, } \\
\text { RBC, WBC and platelet count) and automated differe }\end{array}$ & 713,426 & $\$ 14,268,671$ & $\$ 20$ & pre-1990 \\
\hline 84443 & Thyroid stimulating hormone (TSH) & 338,683 & $\$ 10,455,861$ & $\$ 31$ & pre-1990 \\
\hline 80054 & $\begin{array}{l}\text { Comprehensive metabolic panel This panel must } \\
\text { include the following: Albumin (82040) Bilirubin, tota }\end{array}$ & 398,899 & $\$ 9,684,817$ & $\$ 24$ & 1998 \\
\hline 88307 & $\begin{array}{l}\text { Level V - Surgical pathology, gross and microscopic } \\
\text { examinationAdrenal, ResectionBone - Biopsy/Curet }\end{array}$ & 43,734 & $\$ 7,610,713$ & $\$ 174$ & pre-1990 \\
\hline 88304 & $\begin{array}{l}\text { LEVEL III - Surgical pathology, gross and } \\
\text { microscopic examinationAbortion, Induced Abscess } \\
\text { Aneurysm }\end{array}$ & 106,460 & $\$ 7,289,114$ & $\$ 68$ & pre-1990 \\
\hline 80092 & $\begin{array}{l}\text { Thyroid panel This panel must include the following } \\
\text { tests: Thyroxine, total (84436) Thyroid hormone }\end{array}$ & 136,737 & $\$ 6,802,368$ & $\$ 50$ & 1993 \\
\hline 85024 & $\begin{array}{l}\text { Blood count; hemogram and platelet count, automated, } \\
\text { and automated partial differential WBC count (C }\end{array}$ & 367,033 & $\$ 6,763,304$ & $\$ 18$ & pre-1990 \\
\hline 84153 & Prostate specific antigen (PSA); total & 186,778 & $\$ 6,431,902$ & $\$ 34$ & 1993 \\
\hline 81000 & $\begin{array}{l}\text { Urinalysis, by dip stick or tablet reagent for bilirubin, } \\
\text { glucose, hemoglobin, ketones, leukocytes, }\end{array}$ & 647,439 & $\$ 5,921,593$ & $\$ 9$ & pre-1990 \\
\hline 88156 & $\begin{array}{l}\text { Cytopathology, smears, cervical or vaginal, (the } \\
\text { Bethesda System (TBS)), up to three smears; screeni }\end{array}$ & 353,172 & $\$ 4,891,132$ & $\$ 14$ & 1993 \\
\hline 80049 & $\begin{array}{l}\text { Basic metabolic panel This panel must include the } \\
\text { following: Carbon dioxide (82374) Chloride (82435) }\end{array}$ & 185,322 & $\$ 4,488,182$ & $\$ 24$ & 1998 \\
\hline 80050 & $\begin{array}{l}\text { General health panelThis panel must include the } \\
\text { following: Comprehensive metabolic panel (80053) Bl }\end{array}$ & 91,758 & $\$ 4,288,761$ & $\$ 47$ & pre-1990 \\
\hline 83036 & Hemoglobin; glycated & 180,492 & $\$ 3,677,163$ & $\$ 20$ & pre-1990 \\
\hline 80058 & $\begin{array}{l}\text { Hepatic function panel This panel must include the } \\
\text { following: Albumin (82040) Bilirubin, total (8224 }\end{array}$ & 162,447 & $\$ 3,541,755$ & $\$ 22$ & pre-1990 \\
\hline 88150 & $\begin{array}{l}\text { Cytopathology, slides, cervical or vaginal; manual } \\
\text { screening under physician supervision }\end{array}$ & 218,682 & $\$ 3,277,182$ & $\$ 15$ & pre-1990 \\
\hline 87086 & Culture, bacterial; quantitative colony count, urine & 164,315 & $\$ 3,023,076$ & $\$ 18$ & pre-1990 \\
\hline 86588 & Streptococcus, screen, direct & 182,842 & $\$ 2,658,488$ & $\$ 15$ & 1993 \\
\hline 85610 & Prothrombin time; & 216,645 & $\$ 2,584,066$ & $\$ 12$ & pre-1990 \\
\hline
\end{tabular}


Table 3

20 post-1990 lab procedures performed in 1998 with highest total cost

\begin{tabular}{|c|c|c|c|c|c|}
\hline cpt & description & $\begin{array}{c}\begin{array}{c}\text { Number of } \\
\text { procs. }\end{array} \\
\end{array}$ & Total cost & Avge. cost & year_added \\
\hline 80054 & $\begin{array}{l}\text { Comprehensive metabolic panel This panel must } \\
\text { include the following: Albumin (82040) } \\
\text { Bilirubin, tota }\end{array}$ & 398,899 & $\$ 9,684,817$ & $\$ 24$ & 1998 \\
\hline 80092 & $\begin{array}{l}\text { Thyroid panel This panel must include the } \\
\text { following tests: Thyroxine, total (84436) Thyroid } \\
\text { hormone }\end{array}$ & 136,737 & $\$ 6,802,368$ & $\$ 50$ & 1993 \\
\hline 84153 & Prostate specific antigen (PSA); total & 186,778 & $\$ 6,431,902$ & $\$ 34$ & 1993 \\
\hline 88156 & $\begin{array}{l}\text { Cytopathology, smears, cervical or vaginal, (the } \\
\text { Bethesda System (TBS)), up to three smears; } \\
\text { screeni }\end{array}$ & 353,172 & $\$ 4,891,132$ & $\$ 14$ & 1993 \\
\hline 80049 & $\begin{array}{l}\text { Basic metabolic panel This panel must include } \\
\text { the following: Carbon dioxide (82374) Chloride } \\
(82435)\end{array}$ & 185,322 & $\$ 4,488,182$ & $\$ 24$ & 1998 \\
\hline 86588 & Streptococcus, screen, direct & 182,842 & $\$ 2,658,488$ & $\$ 15$ & 1993 \\
\hline 81001 & $\begin{array}{l}\text { Urinalysis, by dip stick or tablet reagent for } \\
\text { bilirubin, glucose, hemoglobin, ketones, } \\
\text { leukocytes, }\end{array}$ & 143,869 & $\$ 2,238,765$ & $\$ 16$ & 1996 \\
\hline 88142 & $\begin{array}{l}\text { Cytopathology, cervical or vaginal (any reporting } \\
\text { system), collected in preservative fluid, automate }\end{array}$ & 39,580 & $\$ 1,312,214$ & $\$ 33$ & 1998 \\
\hline 80091 & $\begin{array}{l}\text { Thyroid panel This panel must include the } \\
\text { following tests: Thyroxine, total (84436) Thyroid } \\
\text { hormone }\end{array}$ & 49,692 & $\$ 1,195,475$ & $\$ 24$ & 1993 \\
\hline 86677 & Antibody; Helicobacter pylori & 29,555 & $\$ 1,144,457$ & $\$ 39$ & 1993 \\
\hline 86003 & $\begin{array}{l}\text { Allergen specific IgE; quantitative or } \\
\text { semiquantitative, each allergen }\end{array}$ & 12,236 & $\$ 1,142,655$ & $\$ 93$ & 1994 \\
\hline 81003 & $\begin{array}{l}\text { Urinalysis, by dip stick or tablet reagent for } \\
\text { bilirubin, glucose, hemoglobin, ketones, } \\
\text { leukocytes, }\end{array}$ & 105,628 & $\$ 1,086,876$ & $\$ 10$ & 1993 \\
\hline 88141 & $\begin{array}{l}\text { Cytopathology, cervical or vaginal (any reporting } \\
\text { system); requiring interpretation by physician (Li }\end{array}$ & 43,322 & $\$ 991,082$ & $\$ 23$ & 1998 \\
\hline 82378 & Carcinoembryonic antigen (CEA) & 19,016 & $\$ 778,445$ & $\$ 41$ & 1993 \\
\hline 86701 & Antibody; HIV-1 & 32,618 & $\$ 709,558$ & $\$ 22$ & 1993 \\
\hline 82105 & Alpha-fetoprotein; serum & 20,374 & $\$ 657,742$ & $\$ 32$ & 1993 \\
\hline 83721 & $\begin{array}{l}\text { Lipoprotein, direct measurement; direct } \\
\text { measurement LDL cholesterol }\end{array}$ & 32,098 & $\$ 599,652$ & $\$ 19$ & 1993 \\
\hline 87490 & $\begin{array}{l}\text { Infectious agent detection by nucleic acid (DNA } \\
\text { or RNA); Chlamydia trachomatis, direct probe } \\
\text { techniq }\end{array}$ & 20,490 & $\$ 577,064$ & $\$ 28$ & 1998 \\
\hline 80051 & $\begin{array}{l}\text { Electrolyte panelThis panel must include the } \\
\text { following:Carbon dioxide (82374)Chloride } \\
\text { (82435)Potass }\end{array}$ & 30,626 & $\$ 570,721$ & $\$ 19$ & 1998 \\
\hline 89250 & Culture of oocyte(s)/embryo(s), less than 4 days; & 591 & $\$ 563,148$ & $\$ 953$ & 1996 \\
\hline
\end{tabular}


Table 4

Summary statistics, mortality sample

\begin{tabular}{|l|c|c|c|c|c|}
\hline Variable & $\begin{array}{c}\text { No. of } \\
\text { observati } \\
\text { ons }\end{array}$ & MEAN & STD & MIN & MAX \\
\hline & & & & & \\
\hline mean age at death in 1998 & 570 & 74.56 & 428.85 & 1 & 91 \\
\hline $\begin{array}{l}\text { 1990-1998 change in mean } \\
\text { age at death }\end{array}$ & 570 & 1.18 & 71.82 & -66 & 63.5 \\
\hline $\begin{array}{l}\text { 1990-1998 log change in } \\
\text { number of deaths }\end{array}$ & 570 & 0.1 & 14.93 & -1.79 & 2.58 \\
\hline & & & & & \\
\hline $\begin{array}{l}\text { post-1990 procedures/rx's as } \\
\% \text { of total procedures/rx's in } \\
1998\end{array}$ & & & & & \\
\hline lab & 570 & 0.20 & 2.88 & 0.00 & 0.60 \\
\hline outpatient rx & 422 & 0.19 & 6.56 & 0.00 & 1.00 \\
\hline inpatient rx & 497 & 0.08 & 8.89 & 0.00 & 0.83 \\
\hline diagnostic radiology & 569 & 0.04 & 4.20 & 0.00 & 1.00 \\
\hline surgery & 570 & 0.13 & 7.16 & 0.00 & 0.81 \\
\hline
\end{tabular}

Note: Statistics are weighted by mean number of deaths in 1990 and 1998 
Table 5

30 largest causes of death, 1990 and 1998

\begin{tabular}{|c|c|c|c|c|}
\hline ICD-9 code and name & $\begin{array}{c}\text { mean } \\
\text { number of } \\
\text { deaths, } 1990 \\
\text { and } 1998\end{array}$ & $\begin{array}{c}1990- \\
1998 \\
\text { change } \\
\text { in mean } \\
\text { age at } \\
\text { death } \\
\end{array}$ & $\begin{array}{c}\text { Number of } \\
\text { lab } \\
\text { procedures } \\
\text { in } 1998\end{array}$ & $\begin{array}{c}\text { post-1990 lab } \\
\text { procedures as \% } \\
\text { of total lab } \\
\text { procedures in } \\
1998\end{array}$ \\
\hline (414) Other forms of chronic ischemic. & 248,781 & 0.8 & 106,318 & $19 \%$ \\
\hline (410) Acute myocardial infarction & 221,654 & 1.3 & 14,728 & $22 \%$ \\
\hline (162) Malignant neoplasm of trachea, ... & 148,001 & 1.7 & 33,196 & $16 \%$ \\
\hline (436) Acute but ill-defined cerebrova... & 85,468 & 1.1 & 10,271 & $15 \%$ \\
\hline (429) Ill-defined descriptions/compli... & 73,610 & -0.6 & 14,411 & $18 \%$ \\
\hline (496) Chronic airways obstruction, no... & 73,503 & 1.7 & 19,182 & $23 \%$ \\
\hline (486) Pneumonia, organism unspecified & 71,834 & 1.0 & 24,942 & $17 \%$ \\
\hline (250) Diabetes mellitus & 56,252 & 0.8 & 533,601 & $19 \%$ \\
\hline (153) Malignant neoplasm of colon & 48,469 & 0.7 & 25,991 & $22 \%$ \\
\hline (428) Heart failure & 44,057 & 1.5 & 23,051 & $27 \%$ \\
\hline (174) Malignant neoplasm of female br. & 42,600 & 1.1 & 129,583 & $17 \%$ \\
\hline (427) Cardiac dysrhythmias & 41,830 & 1.7 & 75,205 & $19 \%$ \\
\hline (185) Malignant neoplasm of prostate & 32,307 & 1.7 & 30,621 & $33 \%$ \\
\hline (199) Malignant neoplasm without spec.. & 31,362 & 1.1 & 7,149 & $22 \%$ \\
\hline (157) Malignant neoplasm of pancreas & 26,731 & 0.6 & 6,932 & $15 \%$ \\
\hline (425) Cardiomyopathy & 25,550 & 1.9 & 10,193 & $23 \%$ \\
\hline (571) Chronic liver disease and cirrh... & 25,520 & 0.4 & 22,709 & $19 \%$ \\
\hline (402) Hypertensive heart disease & 24,468 & 0.7 & 25,386 & $22 \%$ \\
\hline (038) Septicemia & 21,231 & 0.3 & 5,704 & $20 \%$ \\
\hline (202) Othr malignant neoplasm of lymp... & 19,797 & 1.7 & 35,796 & $14 \%$ \\
\hline (331) Other cerebral degenerations & 19,392 & 2.5 & 1,194 & $24 \%$ \\
\hline (431) Intracerebral hemorrhage & 19,327 & 1.5 & 1,219 & $26 \%$ \\
\hline (042) Human immunodeficiency virus in... & 18,338 & 3.0 & 34,958 & $41 \%$ \\
\hline (290) Senile and presenile organic ps... & 16,692 & 1.1 & 475 & $22 \%$ \\
\hline (440) Atherosclerosis & 16,669 & 0.2 & 5,894 & $19 \%$ \\
\hline (492) Emphysema & 16,638 & 1.1 & 2,107 & $24 \%$ \\
\hline (441) Aortic aneurysm & 16,375 & 0.6 & 2,369 & $23 \%$ \\
\hline (424) Other diseases of endocardium & 15,766 & 2.7 & 21,795 & $17 \%$ \\
\hline (434) Occlusion of cerebral arteries & 15,214 & 0.5 & 3,270 & $18 \%$ \\
\hline (799) Other ill-defined and unknown c... & 14,873 & 5.5 & 68,369 & $22 \%$ \\
\hline
\end{tabular}


Table 6

Estimates of models of 1990-1998 change in mean age at death

\begin{tabular}{|c|c|c|c|c|}
\hline Model & 1 & 2 & 3 & 4 \\
\hline HIV & included & included & excluded & excluded \\
\hline aqe $_{\text {1990 }}$ & & -0.05044 & & -0.05161 \\
\hline std. err. & & 0.00902 & & 0.00962 \\
\hline t-stat. & & -5.59 & & -5.36 \\
\hline p-value & & $<0.0001$ & & $<0.0001$ \\
\hline & & & & \\
\hline lab innovation & 4.73875 & 2.44398 & 3.81875 & 2.60478 \\
\hline std. err. & 1.25634 & 1.2783 & 1.38762 & 1.36003 \\
\hline t-stat. & 3.77 & 1.91 & 2.75 & 1.92 \\
\hline$p$-value & 0.0002 & 0.0566 & 0.0062 & 0.0562 \\
\hline \begin{tabular}{|l} 
outpatient rx innovation \\
\end{tabular} & 159764 & 1.49814 & 127713 & 157028 \\
\hline $\begin{array}{l}\text { std. err. } \\
\text { sta }\end{array}$ & 0.60348 & $\mid$ & 0.63695 & $\begin{array}{l}1.610<0 \\
0.61799\end{array}$ \\
\hline t-stat. & 2.65 & 2.57 & 2.01 & 2.54 \\
\hline$p$-value & 0.0084 & 0.0104 & 0.0456 & 0.0114 \\
\hline & & & & \\
\hline inpatient rx innovation & 1.25194 & 0.14881 & 1.21932 & 0.13099 \\
\hline std. err. & 0.44078 & 0.46832 & 0.4405 & 0.47161 \\
\hline t-stat. & 2.84 & 0.32 & 2.77 & 0.28 \\
\hline$p$-value & 0.0047 & 0.7508 & 0.0059 & 0.7814 \\
\hline \begin{tabular}{|l|} 
diagnostic radioloqy innovation \\
\end{tabular} & 1.12984 & 1.08233 & 1.02536 & 1.1055 \\
\hline std. err. & 0.80448 & 0.77529 & 0.80589 & 0.77899 \\
\hline t-stat. & 1.4 & 1.4 & 1.27 & 1.42 \\
\hline$p$-value & 0.161 & 0.1635 & 0.204 & 0.1566 \\
\hline \begin{tabular}{|l|} 
surgical innovation \\
\end{tabular} & -0.1945 & 0.45884 & -0.01637 & 0.43252 \\
\hline std. err. & 0.53341 & 0.52712 & 0.54474 & 0.53307 \\
\hline t-stat. & -0.36 & 0.87 & -0.03 & 0.81 \\
\hline$p$-value & 0.7156 & 0.3846 & 0.976 & 0.4176 \\
\hline 1990-1998 chanqe in log no. of deaths & 0.62402 & 1.00554 & 0.78101 & 0.97787 \\
\hline \begin{tabular}{|l} 
std. err. \\
\end{tabular} & 0.2555 & 0.25549 & 0.27444 & 0.26776 \\
\hline t-stat. & 2.44 & 3.94 & 2.85 & 3.65 \\
\hline \begin{tabular}{|l}
$p$-value \\
\end{tabular} & 0.015 & $<.0001$ & 0.0047 & 0.0003 \\
\hline \begin{tabular}{|l|} 
Intercept \\
\end{tabular} & -0.23337 & 3.91213 & -0.03623 & 3.96179 \\
\hline \begin{tabular}{|l} 
std. err. \\
\end{tabular} & 0.30767 & \begin{tabular}{|l|l|}
0.79828 \\
0.721
\end{tabular} & 0.33244 & 0.81172 \\
\hline t-stat. & -0.76 & 4.9 & -0.11 & 4.88 \\
\hline$p$-value & 0.4486 & $<.0001$ & 0.9133 & $<.0001$ \\
\hline & & & & \\
\hline R-Square & 0.0885 & 0.1557 & 0.0728 & 0.1362 \\
\hline dep. var. mean & 1.17699 & 1.17699 & 1.16012 & 1.16012 \\
\hline weight & N DEATH & N DEATH & $\mathrm{N}$ DEATH & $\mathrm{N}$ DEATH \\
\hline $\mathrm{N}$ & 401 & 401 & 400 & 400 \\
\hline
\end{tabular}


Table 7

Summary statistics, disability sample

\begin{tabular}{|c|c|c|c|c|c|}
\hline Variable & $\begin{array}{c}\text { No. of } \\
\text { observations }\end{array}$ & MEAN & STD & MIN & MAX \\
\hline$\%$ of people who missed work in 1996 & 335 & 0.13 & 172.83 & 0.01 & 1 \\
\hline $1996-2003$ change in \% of people who missed work & 335 & -0.01 & 65.36 & -0.46 & 0.43 \\
\hline$\%$ of people with bed days in 1996 & 335 & 0.14 & 164.51 & 0 & 0.79 \\
\hline $1996-2003$ change in \% of people with bed days & 335 & -0.01 & 74.49 & -0.46 & 0.48 \\
\hline $1996-2003$ change in log of no. of people with condition & 335 & 0.12 & 764.96 & -2.79 & 1.94 \\
\hline \multicolumn{6}{|l|}{$\begin{array}{l}\text { post-1996 procedures/rx's as \% of total procedures/rx's in } \\
2003\end{array}$} \\
\hline $\mathrm{lab}$ & 335 & 0.19 & 194.48 & 0 & 0.72 \\
\hline outpatient rx & 335 & 0.12 & 98.03 & 0 & 1 \\
\hline inpatient rx & 335 & 0.02 & 73.65 & 0 & 0.46 \\
\hline diagnostic radiology & 335 & 0.02 & 61.44 & 0 & 0.56 \\
\hline surgery & 335 & 0.07 & 181.25 & 0 & 0.81 \\
\hline
\end{tabular}

Note: Statistics are weighted by mean of number of people with condition in 1996 and 2003 
Table 8

Estimates of models of 1996-2003 change in \% of people who missed work or had bed-days

\begin{tabular}{|c|c|c|c|c|}
\hline Model & 1 & 2 & 3 & 4 \\
\hline Disability measure & Missed work & $\begin{array}{c}\text { Any bed } \\
\text { days }\end{array}$ & $\begin{array}{c}\text { Missed } \\
\text { work }\end{array}$ & $\begin{array}{l}\text { Any bed } \\
\text { days }\end{array}$ \\
\hline initial rate of disability & & & -0.18034 & -0.19522 \\
\hline std. err. & & & 0.02152 & 0.02443 \\
\hline t-stat. & & & -8.38 & -7.99 \\
\hline$p$-value & & & $<.0001$ & $<0.0001$ \\
\hline \begin{tabular}{|l|} 
lab innovation \\
\end{tabular} & -0.04824 & -0.04095 & -0.00376 & 0.00601 \\
\hline std. err. & 0.01985 & 0.02285 & 0.0188 & 0.02174 \\
\hline t-stat. & -2.43 & -1.79 & -0.2 & 0.28 \\
\hline$p$-value & 0.0156 & 0.074 & 0.8417 & 0.7824 \\
\hline $\begin{array}{l}\text { outpatient rx innovation } \\
\end{array}$ & -0.07086 & -0.06495 & -0.02773 & -0.0125 \\
\hline std. err. & 0.03691 & 0.04249 & 0.03393 & 0.03947 \\
\hline t-stat. & -1.92 & -1.53 & -0.82 & -0.32 \\
\hline$p$-value & 0.0558 & 0.1274 & 0.4145 & 0.7518 \\
\hline inpatient rx innovation & 0.05445 & 0.02185 & 0.01925 & 0.0611 \\
\hline std. err. & 0.0481 & 0.05537 & 0.04391 & 0.05096 \\
\hline t-stat. & 1.13 & 0.39 & 0.44 & 1.2 \\
\hline$p$-value & 0.2584 & 0.6934 & 0.6614 & 0.2315 \\
\hline \begin{tabular}{|l} 
diagnostic radiology innovation \\
\end{tabular} & 0.03827 & -0.07427 & -0.01819 & -0.06693 \\
\hline std. err. & 0.06242 & 0.07187 & 0.05712 & 0.06584 \\
\hline t-stat. & 0.61 & -1.03 & -0.32 & -1.02 \\
\hline$p$-value & 0.5403 & 0.3022 & 0.7504 & 0.3101 \\
\hline surgical innovation & 0.03326 & 0.0382 & 0.06655 & 0.0674 \\
\hline std. err. & 0.02055 & 0.02366 & 0.01909 & 0.02198 \\
\hline t-stat. & 1.62 & 1.61 & 3.49 & 3.07 \\
\hline p-value & 0.1066 & 0.1073 & 0.0006 & 0.0023 \\
\hline 1996-2003 change in log no. of conditions & -0.00411 & 0.00479 & -0.01541 & -0.00021393 \\
\hline std. err. & 0.00501 & 0.00577 & 0.00475 & 0.00532 \\
\hline t-stat. & -0.82 & 0.83 & -3.24 & -0.04 \\
\hline$p$-value & 0.413 & 0.4073 & 0.0013 & 0.968 \\
\hline Intercept & 0.00421 & 0.00805 & 0.01548 & 0.01661 \\
\hline std. err. & 0.00703 & 0.00809 & 0.00652 & 0.00749 \\
\hline t-stat. & 0.6 & 1 & 2.37 & 2.22 \\
\hline p-value & 0.5497 & 0.3202 & 0.0182 & 0.0272 \\
\hline & & & & \\
\hline R-Square & 0.0475 & 0.0281 & 0.2159 & 0.1869 \\
\hline dep. var. mean & -0.00989 & -0.00586 & -0.00989 & -0.00586 \\
\hline weight & N_COND & N_COND & N_COND & N_COND \\
\hline $\mathrm{N}$ & 335 & 335 & 335 & 335 \\
\hline
\end{tabular}

